lalu pergi Buitenzorg (Bogor), melintasi pemandangan alam Priangan (perkebunan, pegunungan), menikmati peninggalan kuno berupa candi (Borobudur, Prambanan), mengunjungi keraton Yogya dan Solo, Surabaya, menuju Tosari, pegunungan Bromo, lalu menyeberang ke Bali. Demikian pula dengan objek turisme yang disarankan untuk dikunjungi oleh para turis. Dengan kata lain, dalam kurun waktu cukup panjang itinerarionya tidak berubah sama sekali.

Para turis juga disuguhi aneka kebudayaan di Jawa seperti wayang orang, wayang kulit, musik angklung, musik torankong, kerajinan tangan (keris, batik). Mereka juga dilayani sarana transportasi modern, seperti kereta api dan kapal laut (KPM) bahkan pesawat udara (KNILM). Sarana pendukung lainnya, sarana akomodasi yaitu hotel bertaraf internasional. Semua ini merupakan bagian dari kebijakan pemerintah kolonial yang mengatur, mengontrol turisme di Hindia Belanda.

Dalam kaitannya dengan sumber sejarah, perjalanan Yoshichika Tokugawa dan rekan ilmuwan lainnya dalam The Fourth Pasific Science Congress- Java 1929 di Bandung dan Bogor dimuat dalam Jaarverslag Vereeniging Toeristenverkeer 1929. Namun tentunya dokumen resmi pemerintah itu bersifat kaku, kering, serta bersifat formal. Padahal, catatan perjalanan diharapkan dapat mengungkapkan informasi yang lebih mendalam.

Namun, untuk menggunakan catatan perjalanan sebagai sumber sejarah kita harus mengetahui latar belakang penulisnya (umur, jabatan, gender, kepercayaan, dan lain-lain). Dengan kata lain, para peneliti ditantang untuk melatih dirinya membaca apa yang ada di benak penulisnya dan bukan sekadar membaca produk dalam bentuk rangkaian naratif. Tentunya di sini diperlukan pisau analisis lain.

Dilengkapi dengan foto (koleksi pribadi dan koleksi lain), peta, dan indeks membuat buku ini cukup menarik dan informatif. Hanya saja angka Romawi di halaman lampiran untuk foto dan indeks sedikit mengganggu.

Achmad Sunyajadi

Pengajar Program Studi Belanda,

Fakultas Ilmu Pengetahuan Budaya Universitas Indonesia

\title{
Warung Kopi dan Pemikiran Habermas
}

Brian Cowan. The Social Life of Coffee: The Emergence of the British Coffeehouse. (New Heaven \& London:Yale University Press, 2005) xi +364 halaman. 
Bagaimana menghubungkan public spherenya Habermas dengan minum kopi dalam perspektif sejarah? Brian Cowan menjawabnya melalui penelitian serius mengenai kebiasaan minum kopi dan kehadiran kedai kopi di Inggris dalam kaitannya dengan perubahan sosial pada era Elizabeth (1600) sampai George I (1720). Hasilnya, sebuah buku setebal 364 halaman termasuk daftar pustaka dan indeks.

Cowan memulai bahasannya dengan mengedepankan sejumlah pertanyaan penting. Kopi berasal dari tradisi timur yang diperkenalkan ke Eropa oleh kalangan Ottoman. Cowan bertanya, mengapa orang Inggris jatuh cinta pada cita rasa yang asing, dan bahkan dari tradisi nonChristian yang datang pada abad ke-17? Mengapa kopi sukses di Inggris sementara, katanya, minuman lain yang sama-sama eksotis tidak sehebat kopi pengaruhnya? Lebih daripada itu, ia pun ingin mencari penjelasan terbaik mengenai kaitan kehadiran institusi sosial baru yang terkait dengan kehadiran warung kopi pada saat itu. Untuk itu, katanya, kita harus mendekatinya dari segi mental, politis, dan struktur ekonomi harian masyarakat yang bersangkutan.

Cowan membagi bukunya ke dalam tiga bab utama. Pertama, "Coffee from Curiosity to Commodity". Pada bagian ini, penulis membahas asal-usul masuknya kopi ke dalam kesadaran publik masyarakat urban di Inggris. Menurut Cowan, kopi muncul di Inggris semula bukan sebagai komoditas, tetapi sebagi bagian penting dari sebuah zaman ketika orang Inggris sedang terpesona oleh berbagai barang temuan yang merupakan hasil dari persentuhannya dengan dunia Timur. Pada masa ini sekolompok kolektor barang "aneh" serta para etnografer dan sejarawan tengah asyik menjelaskan berbagai hal yang menyangkut ketimuran. Kopi pun masuk dalam semangat zaman seperti itu. Yang berperan dalam pengenalan kopi adalah 'virtuoso'. Kelompok elite yang senantiasa memiliki perhatian pada sastra, dan kebudayaan dari zaman Renaissance.

It was virtuoso who led the way in spurring consumer interest in coffee. The virtuoso travelers and, even more so, the virtuoso readers of travel literature and accounts of the commodities of exotic cultures, were the first Englishmen to learn about, write about, and indeed to drink coffee (hlm. 14).

Pada bagian ini pun dijelaskan bahwa kemudian kopi menjadi perhatian para pedagang.

Setelah menjelaskan asal-usul kedatangan kopi ke Inggris, pada bagian kedua, Cowan kemudian menjelaskan ihkwal kedai kopi di Inggris: Inventing the Coffeehouse. Di sini mulai kelihatan beberapa konsep yang berhubungan dengan pandangan Habermas. Kopi yang semula hanya dikenal oleh para pengelana dan peneliti Inggris itu kemudian menjadi bagian dari aktivitas publik. Lagi-lagi, kedai kopi di Inggris pada masa awalnya tidak dapat dilepaskan dari para virtuoso yang menjadi patron utama (hlm. 87) warung kopi terkenal pada waktu itu. Warung kopi menyandarkan diri kepada para virtuoso yang senantiasa tertarik pada hal-hal baru dan eksotis. Melalui mereka warung kopi memiliki daya tarik bagi pelanggan. Dan, daya tarik itu sering diwujudkan dengan sangat eksplisit, misalnya dengan menghadirkan 
cinderamata aneh atau barang milik para virtuoso dipajang di dinding atau langit-langit warung kopi sebagai dekorasi yang mengundang pelanggan. Menurut Cowan, bentuk awal coffeehouse yang didukung para virtuoso ini kemudian menjadi semacam standar untuk membuat coffeehouse yang lain.

Karena para virtuoso mempunyai daya pikat dan pengaruh besar di warung kopi, lama-kelamaan warung kopi menjadi semacam pusat informasi, gosip, tandingan bagi lembaga informasi bahkan lembaga politik yang ada. Wacana eksklusif para virtuoso dapat dengan mudah dinikmati masyarakat urban sepanjang mereka mampu membeli secangkir kopi. Denyut warung kopi seperti ini menarik perhatian kalangan borjuis yang semula hanya berkeliaran di hotel dan restoran mewah di London. Cowan kemudian melihat sebuah interaksi penting antara ilmuwan dan kalangan borjuis yang disebutnya sebagai 'bourgeoisification" (hlm. 89). Sebuah proses yang membawa ilmuwan berkontak ria dengan dunia komersial London. Karya tulis dan koleksi para virtuoso kemudian dengan bebas diperjualbelikan. Tak lama kemudian, coffeehouse menjadi tempat yang lebih publik dan komersial. Hal ini tentu tidak disukai oleh sebagian virtuoso yang lebih suka pada lingkungan eksklusifnya. Akan tetapi, kenyataan menunjukkan bahwa tidak semua virtuoso mampu membiayai penelitiannya. Bahkan sebagian masyarakat yang ingin menjadi virtuoso kelas bawah justru datang ke coffeehouse untuk mendapatkan sumber informasi dan data yang mereka perlukan

Bahasan Cowan pada Bab 3, "Civilizing the Coffehouses", menjadi salah satu bagian yang paling menarik dalam bukunya. Kedai kopi yang semula hanya untuk mencicipi minuman sambil melihat barang "aneh" koleksi para virtuoso dari perjalanannya ke dunia Timur kemudian menjadi tempat belajar dan mendapatkan informasi bagi masyarakat urban Inggris. Warung kopi berlomba-lomba menyajikan barang cetakan yang mutakhir bagi pelanggannya. Coffehouses pun kemudian dibanjiri 'teks' yang senantiasa dicari oleh masyarakat sebelum berangkat kerja. Bahkan, kalau ada kedai kopi yang baru buka pukul 9, katanya, patut dicurigai keandalannya dalam menyediakan informasi. Alasannya, umumnya para pekerja di kota-kota Inggris waktu itu sudah keluar rumah pada pukul 6 dan, sebelum masuk kerja, mereka merasa harus mampir ke coffeehouses untuk ngopi dan mendapatkan koran baru, terbitan, dan gosip yang mereka perlukan. Dampaknya, coffeehouses bukan hanya untuk mendapatkan berita tetapi juga untuk menyebarkan berita, termasuk yang mempunyai dampak politis. Tak heran, penguasa kemudian membuat regulasi.

Mengapa coffeehouses begitu mengkhawatirkan sebagian penguasa dan mengapa kedai kopi ternyata tetap mampu bertahan di tengah regulasi yang dicanangkan istana? Kedai kopi bertahan karena banyak pihak membutuhkan kehadirannya termasuk legislator, politisi, dan masyarakat pada umumnya. Pada bagian ini, Cowan memberikan tinjauan yang menarik tentang tumbuhnya partisipasi politis publik di kalangan masyarakat urban. Ada kecenderungan, Cowan meneruskan pikiran Habermas, bahwa coffeehouse berfungsi sebagai tempat pertukaran informasi aktual yang mengaburkan 
sebagian asal-usul atau status orang ketika masuk ke kedai kopi. Semua orang dapat berbicara hal yang sama tanpa terlalu terpaku pada kedudukan yang bersangkutan. Dengan demikian, rasionalitas dalam berwacana mulai terbangun. Padahal, sebelumnya, sejumlah wacana publik sangat ditentukan oleh tradisi istana dan dipengaruhi oleh karisma tokoh tertentu.

Kendati sempat "dimusuhi" istana dan dikenai regulasi penggunaan ruang publik, warung kopi pada masa itu terus bertahan karena di dalamnya terlibat orang-orang "dalam" yang juga tergila-gila pada kopi dan ingin ikutan "ngopi" dengan publik dalam situasi yang cair dan rasional, dan menghibur tentunya. Regulasi dan produk politik yang dibuat untuk membatasi warung kopi di Inggris sebenarnya melibatkan pula cita rasa dan campur tangan elite politis yang juga tertarik pada kehadiran warung kopi sebagai wahana pendorong partisipasi politis masyarakat. Di sinilah, Cowan berhasil menunjukkan bahwa sebuah "ruang" di tengah masyarakat tidak hadir begitu saja, tetapi ditemukan (invented) dan dinegosiasikan (negotiated). Institusi sosial yang baru secara kreatif dapat ditumbuhkan dalam masyarakat untuk membantu dan mewakili kepentingan mereka di tengah kepentingan ekonomi, politik, budaya, elite, dan masyarakat awam pada umumnya. Institusi itu baru efisien jika mampu mewadahi pertarungan wacana secara cair, santai, dan rasional tanpa harus mempertimbangkan status sosial yang terlibat. Lebih bagus lagi jika mampu memuaskan kenikmatan seperti yang dilakukan para virtuoso.

Sejarah kopi dan warung kopi masih perlu diteliti lebih lanjut, bahkan di Indonesia sekalipun. Selain isu culture stelsel yang "menambal" utang Belanda dengan keringat kopi inlander, kita pun ingin tahu apakah warung kopi di Indonesia punya potensi untuk menjadi ruang publik seperti yang dibayangkan Cowan.

Dengan demikian, menurut hemat saya, penelitian partisipasi publik yang memanfaatkan unsur-unsur baru dalam masyarakat masih perlu diperhatikan masyarakat Indonesia. Mengenai hal ini saya lantas teringat upaya masyarakat dan pemerintah untuk menghidupkan Kelompencapir (Kelompok Pembaca dan Pirsawan) pada masa Orde Baru. Idenya cukup bagus, tetapi karena tidak santai dan terfokus pada pejabat, kegiatan itu menjadi sesuatu yang menjauh dari publik.

Tengoklah Posyandu. Posyandu, lumayan, lebih bertahan ketimbang Kelompencapir karena kaum ibu, selain datang untuk menimbangkan badan anak dan dirinya, juga untuk bergosip dan menanyakan masalah kesehatan kepada yang lebih paham di antara mereka, dan kalau beruntung tentu bisa bertanya kepada petugas kesehatan desa yang datang. Kendati peran pemerintah dalam Posyandu misalnya cukup besar, masyarakat melihatnya sebagai tempat yang "enak" untuk didatangi, maka umur institusi sosial ini lebih lama daripada Kelompencapir.

Demikian pula dalam hal kopi, Cowan menjelaskan dengan gaya Habermas bahwa partisipasi publik yang "cair" dan "asyik", yang dapat melibatkan semua lapisan sosial, perlu "diseduh" dan "dikocek" terus. Terbukti bahwa, 
kendati tidak menghasilkan revolusi, warung kopi mempunyai peran penting dalam membangun civil society, katanya.

Itulah debat warung kopi.

T. Christomy

Pengajar PS Indonesia \&

Associate Professor Malay Indonesian Departement Hankuk University of Foreign Studies, Seoul

\section{Irigaray's Vaginasophia}

Luce Irigay. Aku, Kamu, Kita: Belajar Berbeda, penerjemah Rahayu Hidayat (Jakarta: KPG dan Forum Jakarta Paris, 2005), 210 halaman.

"Spesies manusia dibagi atas dua jenis yang menjamin produksi dan reproduksi. Keinginan untuk menghilangkan perbedaan jenis kelamin sama dengan pembantaian umat manusia." (Aku, Kamu, Kita: Belajar Berbeda, hlm.11)

Subjektivitas dalam kosakata filsafat Barat sungguh sebuah mantra suci rasionalitas. Padahal, saya termasuk orang yang percaya bahwa subjektivitas tidak lahir dari rasionalitas. Subjektivitas adalah nama lain dari penaklukan. Penegasan diri di hadapan objek adalah sebuah invasi diam-diam. Objek dibisukan dari segala tuturan pribadi tentang dirinya. Ia tidak dimusnahkan. Hanya dibisukan. Sebab itulah bukti kemenangan sejati subjektivitas di hadapan yang liyan. Penegasan diri seorang laki-laki di hadapan istrinya bisa saja berbunyi, "Sayang, apakah kau menikmatinya seperti halnya aku?" Perempuan tidak mampu bersuara sendiri perihal kenikmatan. Ia mesti berbicara dalam terminologi kenikmatan punya laki-laki. Ia adalah yang terkastrasi dan mendambakan penisnya kembali, menurut Freud. Kenikmatan sesungguhnya adalah penetrasi beruntun penis ke dalam vagina. Bukan sebaliknya, sebab itu tidak mungkin. Perempuan selamanya tertutup dari kenikmatan pribadi dalam berhubungan seksual. Ia telah kehilangan jati dirinya sebagai yang liyan secara seksual.

Adalah Luce Irigaray, feminis arus ketiga, berjuang mempertahankan ke-liyan-an perempuan di hadapan agresi subjektivitas laki-laki. Dalam opus magnum-nya, Speculum, ia menyusun satu bab berjudul Any Theory of the 'Subject' Has Always Been Appropriated by the 'Masculine. Tidak ada satu pun teori tentang subjek yang netral. Subjektivitas perempuan terusmenerus disangkal dalam sejarah pemikiran. Ini pun menyelinap ke dalam 